\title{
BIBLIOTECA ESCOLAR NA VISÃO DAS CRIANÇAS DO ENSINO FUNDAMENTAL
}

\author{
Mariza Inês da Silva Pinheiro ${ }^{1}$ \\ mariza.ines@terra.com.br
}

\begin{abstract}
Resumo: O estudo realizado teve como propósito conhecer a realidade vivenciada por alunos do Ensino Fundamental na Biblioteca da Escola Estadual Professora Renilda Silva Moraes, localizada na cidade de Rondonópolis, Mato Grosso. Para tanto, propusemo-nos a verificar o nível de satisfação dos alunos, com relação à organização geral da biblioteca, o sistema de classificação em cores, as atividades de incentivo à leitura e interação entre aluno/bibliotecário/professor. A busca das informações foi através de um questionário com perguntas abertas e fechadas. A biblioteca escolar deve ser considerada um espaço com função educativa de uma escola e, portanto, deve estar inserida nos projetos pedagógicos como uma aliada no processo ensino-aprendizagem. Com relação às atividades desenvolvidas para o incentivo à leitura, constatou-se que a biblioteca oferece diversas atividades de motivação, tais como: a hora do conto, cantinho da leitura; produção textual; interpretação de textos; carrinho da leitura; teatro; leitor do ano, danças, confecção de livros, concurso de desenhos, seleção de assuntos em revistas, premiação leitor do ano. Assim, os resultados revelaram que os alunos aprovam todas as atividades proposta se estão muito satisfeitos pelo trabalho realizado na Biblioteca.
\end{abstract}

Palavras-chave: Biblioteca escolar. Satisfação do usuário. Incentivo à leitura.

\section{INTRODUÇÃO}

A biblioteca escolar é um ambiente educacional que está inserido na escola e, portanto, deve fazer parte dos projetos pedagógicos para aprimorar e estimular nas ações de leitura. A preocupação com este ambiente tem sido pauta de muitos debates nas literaturas e em eventos, para que seja uma biblioteca viva de modo a despertar o interesse da leitura na criança e no jovem. Mas nem sempre essas iniciativas são colocadas na prática. Assim, a biblioteca escolar deve ser um ambiente agradável, que assuma o perfil da comunidade escolar, de maneira que as atividades sejam favoráveis ao incentivo à leitura, à pesquisa e à promoção de ações culturais e sociais por meio da ação pedagógica.

A família deve ser a primeira a oferecer o livro literário à criança, desde os primeiros anos de vida, mas, infelizmente, em muitos casos, o primeiro contato com o livro literário acontece na biblioteca escolar, que seria o segundo ambiente de incentivo à leitura. Neste contexto, é fundamental que os bibliotecários e os professores assumam um relacionamento interativo, envolvendo o aluno no programa escolar, estimulando o gosto pela leitura.

A pesquisa realizada apontou alguns aspectos do espaço físico e da organização do ambiente da biblioteca sempre considerando as características e necessidades de seus frequentadores como a importância do bibliotecário escolar e do professor no desenvolvimento de atividades que propiciem a motivação à leitura.

\footnotetext{
${ }^{1}$ Doutora em Documentação pela UC3M na Espanha. Mestre em Engenharia de Produção pela Universidade Federal de Santa Maria, RS. Especialista em Desenvolvimento e Gerenciamento de Sistemas de Informação pela Fundação Universidade Federal do Rio Grande, RS. Graduada em Biblioteconomia pela Fundação Universidade Federal do Rio Grande, RS. Professora Efetiva do Curso de Biblioteconomia da Universidade Federal de Mato Grosso.
} 
Mostra também, através de literaturas pesquisadas, o valor da biblioteca escolar, a importância da utilização de uma metodologia de Classificação em cores e as atividades de incentivo à leitura e interação (aluno, bibliotecário e professor).

Para que se possa satisfazer a necessidade das crianças e dos adolescentes é justo que todo o processo organizacional da biblioteca escolar (serviços, atendimento, lazer) seja mais atrativo, prestativo e facilite encontrar as obras nas estantes com rapidez.

Logo, a biblioteca deve ser um espaço acolhedor que visa estimular a comunidade e usuários na busca pelo conhecimento.

O objetivo principal do estudo foi conhecer a realidade vivenciada na Biblioteca da Escola Estadual Professora Renilda Silva Moraes pelos alunos. O objetivo específico foi verificar o nível de satisfação e insatisfação desses usuários em relação aos seguintes indicadores: organização, atendimento, serviços, acervo, ambiente físico, atividades de incentivo à leitura e interação (professor e bibliotecário).

A pesquisa pretende contribuir não somente com a escola, mas com pesquisadores da área e todos aqueles que tenham interesse por este assunto e que possam se beneficiar dos resultados para direcionar seus estudos e pesquisas.

Partindo do pressuposto que incentivar à leitura é uma forma de estimular leitores críticos e bem informados, surgiram as seguintes perguntas de pesquisa: Será que a biblioteca apresenta uma organização adequada às necessidades informacionais e a leitura aos alunos? Quais são os projetos de incentivo à leitura que a biblioteca oferece aos alunos? Será que os alunos aprovam as atividades de incentivo à leitura pela biblioteca? Qual o nível de satisfação da organização, serviços e atendimento por parte dos alunos referente à biblioteca?

\section{BIBLIOTECA ESCOLAR E O ESPAÇO DE MEDIAÇÃO DE LEITURA}

Para Hillesheim e Fachin (2003-2004), a biblioteca escolar é uma fonte de informação riquíssima para o processo de ensino-aprendizagem da criança e adolescente. Neste enfoque, as autoras colocam como um lugar onde a informação encontra-se armazenada em diferentes tipos de suportes e formas de acesso. Depois disso, a biblioteca pode ser vista como um espaço de troca de conhecimento, de busca por informações, de pesquisa, de debates, de lazer, etc.

A biblioteca é um espaço que liga os conhecimentos gerados no mundo e a comunidade docente e discente. Côrte e Bandeira (2011, p. 8) descrevem a biblioteca escolar "como um espaço de estudo e construção do conhecimento, que coopera com a dinâmica da escola, desperta o interesse intelectual, favorece o enriquecimento cultural e incentiva o hábito pela leitura".

Seu objetivo principal é incentivar, disseminar o gosto pela leitura e orientar os alunos de modo que esses aprendam a manusear e utilizar informação em suas vidas.

$\mathrm{Na}$ biblioteca encontram-se informações transmitidas em diversos meios informacionais como, por exemplo, livros, periódicos (artigos, jornais, revistas), Internet, entre outros, que possibilitam o aprendizado, a formação do aluno crítico e sua interação na sociedade em que vive. Na visão de Campello (2005, p. 11).

A biblioteca escolar é, sem dúvida, o espaço por excelência para promover experiências criativas de uso de informação [...] a biblioteca pode, através de seu programa, aproximar o aluno de uma realidade que ele vai vivenciar no seu dia-a-dia, como profissional e como cidadão [...]. 
Percebe-se a partir das contribuições acima que, a biblioteca escolar tem a real função de incentivar a leitura e a pesquisa escolar para dar suporte à aprendizagem. Ela tem em sua composição um acervo bibliográfico. A organização deste acervo deve apresentar um conjunto de indicadores, conforme demonstra Campello et al. (2010, p. 10).

Parte 1: Um conjunto de indicadores relativos a $\bullet$ espaço físico, $\bullet$ acervo, $\bullet$ computadores com acesso à internet, $\bullet$ organização do acervo, $\bullet$ serviços e atividades $\bullet$ pessoal, que representam o nível básico em que uma biblioteca deve funcionar, e aponta o nível exemplar, isto é, um horizonte a ser alcançado. Parte 2: Um instrumento de avaliação e planejamento que amplia os indicadores acima mencionados, permitindo que a escola analise e avalie detalhadamente sua biblioteca, e trace metas e prazos para seu aperfeiçoamento.

No planejamento de uma biblioteca devem ser proporcionadas a acessibilidade ao ambiente e a liberdade de acesso às obras bibliográficas. Assim, faz-se necessária uma boa estrutura.

Cada biblioteca tem sua própria organização, mas é importante que, em todas elas, se queremos que a criança se aproxime dos livros e da leitura e deles desfrute o máximo, o acesso seja sistemático, dinâmico e planejado com coerência e preocupação pedagógica. $\mathrm{E}$, quanto mais o aluno puder, nesse espaço, escolher livremente suas leituras, melhor (BALDI, 2009, p.18).

Uma boa organização da biblioteca é importante, mas o bibliotecário não pode se prender somente a esta questão, deve pensar de um modo ampliado e diversificado, com a intenção de divulgar e motivar a utilização de todos os serviços, repassando aos usuários informações inerentes à missão da mesma.

Além disso, um ambiente acolhedor estimula as crianças a se sentirem confortáveis em frequentá-la, facilitando a busca pelas obras nas estantes. Segundo Campello (2012, p. 36)

A aprendizagem por meio da biblioteca escolar é influenciada por uma variedade de fatores (recursos, estrutura organizacional, propostas pedagógicas) e atores como professores, administradores e estudantes, isto é, pela "Cultura escolar" que compõe o contexto da biblioteca.

As obras classificadas em cores também é uma forma de organização do acervo. Na opinião de Pinheiro (2009), além de a biblioteca ter um espaço agradável, divertido e colorido, ela necessita de uma classificação acessível às crianças. São fatores que devem estar em conjunto para uma boa satisfação do usuário. Isso está confirmado nas palavras de Pinheiro e Rodrigues (2014, p. 268) segundo os quais a atual gestora da Escola Estadual Professora Renilda Silva Moraes, "apóia e reconhece a importância da organização do acervo por cores, às ações desenvolvidas, as quais facilitam tanto o trabalho das bibliotecárias quanto a autonomia dos alunos, pois estes podem escolher a literatura de suas preferências". De igual modo apontam Cortê e Bandeira (2011, p. 36).

A biblioteca deve funcionar com uma estrutura mínima que permita a organização de trabalhos de forma coerente com os princípios da biblioteconomia e das organizações, respeitando o tamanho de cada escola e o número de alunos.

A organização pela classificação em cores é muito pouco divulgada, como relata Pinheiro (2009, p. 169) “[...] é oportuno enfatizar-se que esta metodologia é inédita no Estado de Mato Grosso e pode se até dizer no Brasil". 
Em nossa opinião, por meio de estágios do curso de Biblioteconomia, pode-se entender este processo e conhecer melhor a classificação em cores, criada pela professora Dra. Mariza Inês da Silva Pinheiro e implementada para organização nas bibliotecas escolares no município de Rondonópolis.

A utilização das cores, para classificar as obras do acervo, é uma alternativa considerada eficaz para facilitar o acesso ao material bibliográfico desejado, pois cada cor representa um gênero da literatura contribuindo para o desenvolvimento e o interesse principalmente das crianças que estão em fase de alfabetização, na busca de novos livros.

As cores, no ambiente de uma biblioteca escolar, tornam-se mais atrativas e transmitem alegria, aproximando os pequenos usuários da biblioteca. Nas palavras de Pinheiro (2009, p. 167) “[...]é necessário abrir caminhos, criar condições e implantar ações que possam estimular e motivar a criança a frequentar uma biblioteca por prazer e, consequentemente, adquirir nas leituras um melhor aprendizado".

\section{ATIVIDADES DE MEDIAÇÃO: INCENTIVO À LEITURA}

A partir da alfabetização da criança e, também, durante toda a sua vida escolar, é necessário favorecer o contato direto com vários tipos de materiais bibliográficos, tais como livros, gibis, literaturas, jornais e revistas. Essa é uma estratégia é muito importante, pois fica mais fácil de despertar a curiosidade para a leitura e a escrita.

A nosso ver, as atividades de incentivo à leitura desenvolvem no leitor o gosto pela leitura e pelo livro, motivando-o a conhecer os diversos tipos de textos e escritas, buscando conhecer os diversos tipos de literatura. E a leitura, seja ela literária ou não, traz benefícios no desenvolvimento cognitivo do indivíduo.

Na biblioteca, ações como "Hora do Conto" reforçam a prática diária da leitura. A hora do conto é uma das atividades que mais estimula a criança no incentivo à leitura. Percebe-se que elas viajam no mundo da imaginação e que podem desenvolver o gosto pela arte de cantar, contar e recontar histórias. Essa atividade requer do ouvinte bastante atenção, socialização e interpretação.

Para promover o incentivo da leitura, os agentes, professores e bibliotecários, precisam reconhecer qual é o interesse de leitura dos alunos, quais são os fatores que influenciam nesses interesses e outros aspectos para compreender o que melhor pode promover essa ação. Na visão de Baldi (2009, p. 8)

É preciso alimentar a imaginação de nossos alunos, compartilhar leituras com eles e oferecer-lhes experiências de fricção para que descubram os encantos da literatura como uma forma de arte que possibilita conhecerem melhor a si mesmos, o mundo e aos que os cercam, para que se tornem pessoas mais sensíveis, mais críticas, mais criativas.

A família também é de grande importância nesse processo, uma vez que é a responsável por passar os primeiros valores e costumes para a criança, mas nem sempre é o que ocorre. Vale lembrar o que diz a Lei n 9.392 de 20 dezembro de 1996 - LDB (Lei de Diretrizes e Bases da Educação Nacional), a respeito dos processos formativos que se desenvolvem na vida familiar, na convivência humana, no trabalho, nas instituições de ensino e pesquisa, nos movimentos sociais e organizações da sociedade civil e nas manifestações culturais (Caput, artigo $1^{\circ}$, LDB ou Lei 9.394/96). Segundo o art. $1^{\circ}$ em dois parágrafos, a educação escolar, desenvolve, predominantemente, por meio do ensino, em instituições próprias $\left(\S 1^{\circ}\right) ;[\ldots]$ deverá vincular-se ao mundo do trabalho e a prática social $\left(\S 2^{\circ}\right)$.

Depreende-se a partir desse artigo $1^{\circ}$ que a família é a primeira instituição responsável pela educação da criança, muito antes da escola ou do Estado.

Também em Moro e Estabel (2012, p. 60) defendem que "pais, professores e bibliotecários devem ser partícipes nas ações de leitura, que deveriam se iniciar na família e se implementar na escola e na biblioteca". 


\section{ANÁLISE}

Analisando o propósito do estudo, buscou-se através de um questionário verificar o nível de satisfação e insatisfação dos alunos com relação aos seguintes indicadores: organização, atendimento, acervo, pesquisa, ambiente físico, atividades de incentivo à leitura, participação do professor na biblioteca; e também verificar se o papel desempenhado pelo bibliotecário é satisfatório para a comunidade escolar.

O questionário foi aplicado a 22 alunos do $3^{\circ}$ ano, 18 alunos do $4^{\circ}$ ano e 31 alunos do $5^{\circ}$ ano, totalizando 71 alunos do Ensino Fundamental. A satisfação dos alunos referente a todos os indicadores acima citados foi considerada ótima, pois os que se declararam satisfeitos representam um percentual acima de 90\%, com exceção do espaço físico que apresentou um índice mais baixo. Dos entrevistados, $54,3 \%$ mencionaram como ótimo; $38,3 \%$ bom e 7,3\% regular.

Esse levantamento constatou que a biblioteca proporciona diversas atividades para o incentivo à leitura, tais como: a hora do conto no cantinho da leitura, produção textual, (gibis, poesias, histórias, fábulas), interpretação de textos, paródias, leitura extraclasse; fichas de leitura; estudos em grupos; carrinho da leitura; teatro, leitor do ano, danças, confecção de livros, concurso de desenhos, seleção de assuntos em revistas, premiação leitor do ano.

Tais atividades contam com a participação dos professores e bibliotecárias. Todas voltadas ao incentivo, buscando despertar o gosto pela leitura através dos diversos gêneros literários. Assim, as leituras vêm contribuindo de forma significativa, correspondendo às necessidades informacionais de seus usuários. Algo importante que apareceu durante a pesquisa foi a constatação de que todos consideram importante a interação entre biblioteca e sala de aula, bem como professor e bibliotecário, no sentido de apoio às atividades de incentivo à leitura e à participação dos professores na biblioteca.

Constatou-se, também, que a bibliotecária responsável pelas atividades tem uma boa relação com os alunos, o que favorece e motiva muito mais o acesso dos alunos e outros usuários, pois a forma de tratamento influencia muito no ambiente, principalmente no ambiente de leitura. Infelizmente, em algumas bibliotecas do país, isso não acontece. Uma biblioteca organizada, aconchegante e de acesso fácil ao acervo. Como afirmam Pinheiro e Rodrigues (2014, p.265), "Mas com um diferencial: a leitura é realizada, as retiradas de literaturas são constantes, a presença dos alunos é grandiosa na biblioteca, que mais parece uma "colmeia", ao redor dos livros". Esse resultado mostra que é importante para o bibliotecário ter uma boa relação não só dentro da biblioteca, mas também em todo ambiente escolar.

Quanto à organização do acervo e sua metodologia de classificação em cores, os usuários demonstraram muito satisfeitos. Verificou-se que a forma de organização utilizada no acervo tem suprido todas as necessidades dos alunos, pois pela classificação em cores o ambiente se torna mais alegre, atraente, de forma clara e simplificada.

Com a sinalização em cores na identificação do acervo, leva as crianças a utilizarem o acervo de maneira independente, sentindo-se à vontade para escolher as obras nas estantes conforme o gênero literário.

Com relação ao acervo, disseram que estão satisfeitos com a grande quantidade de títulos literários e a qualidade das obras.

Foi possível verificar também, através desta pesquisa, que o espaço é um indicador a ser mais bem observado pela gestão da escola e governo estadual, embora não tenha sido avaliado de forma negativa. $\mathrm{O}$ mesmo foi citado nas sugestões feitas pelos usuários ao final do questionário como um espaço bom, mas que poderia ser maior para melhor contribuir com a leitura e demais atividades.

Os alunos sugerem também uma maior participação dos professores na biblioteca, não que eles não participem, mas isso os incentivaria muito mais, além de aumentar o grau de utilização desse espaço interativo. Ainda sobre esse fato, os resultados apontaram que $88 \%$ consideram muito bom diante da ressalva dos entrevistados. Assim, para Campello (2003, p.10), professores e bibliotecários, trabalhando juntos planejarão situações de aprendizagem que desafiem e motivem os alunos, acompanhando seus progressos [...]. 
No nosso ponto de vista, trabalhar em conjunto é sempre um desafio, mas é possível para potencializar os objetivos, neste caso em específico, é o incentivo à leitura, visto que não é tarefa fácil diante dos grandes avanços das mídias e das redes sociais. No entanto, a leitura literária sempre terá o seu espaço garantido, principalmente quando estimulada desde as séries iniciais. Somente através da leitura, seja literária ou não, é que conseguiremos desenvolver em nossos alunos o gosto e a criticidade que advêm desse processo, contribuindo para o desenvolvimento de capacidades leitoras de modo a torná-los profícuos e autônomos para o exercício da cidadania. Sob esta perspectiva, Moro e Estabel (2012, p. 60), "a leitura possibilita a descoberta de um novo mundo, navegar por lugares nunca imaginados e a interação do eu com o texto lido é única, pois cada pessoa percebe este texto de uma forma"

\section{CONSIDERAÇÕES FINAIS}

Diante de tudo que foi exposto, um fato importante ficou comprovado, a saber, que a biblioteca cumpre o seu papel enquanto mediadora da informação e da leitura e satisfaz as necessidades de seus usuários.

Esta pesquisa não esgota as discussões sobre esse tema, uma vez que ele está sujeito a novos olhares. Entretanto, tecem-se algumas considerações finais. De um modo geral, a grande maioria dos sujeitos da pesquisa encontra-se satisfeito com os aspectos que contemplam a biblioteca da escola. Contudo, vale reafirmar o que já se disse anteriormente com relação ao espaço da biblioteca, o seu tamanho não é o ideal, no entanto, reconhece-se que este assunto não depende só da equipe escolar, mas de todo um sistema que demanda questões burocráticas e políticas. Assim, é importante dar uma atenção especial para a amplitude desse espaço que proporcionará melhores ofertas de atividades dentro da biblioteca.

Enfim, percebemos que ao apresentar um verdadeiro trabalho de mediação da leitura através de ações educativas e culturais entre bibliotecários, alunos e professores teremos bons leitores.

\section{REFERÊNCIAS}

BALDI, Elizabeth. Leitura nas séries iniciais: uma proposta para formação de leitores de literatura. Porto Alegre: Editora Projeto, 2009.160p.

BRASIL. LDB. Lei 9394/96. Lei de Diretrizes e Bases da Educação Nacional. Disponível em:<w.mec.gov.br>. Acesso em: 20 jun. 2015.

CAMPELLO, Bernadete Santos et al. A Biblioteca Escolar: temas para uma prática pedagógica. 2. ed. Belo Horizonte: Autêntica, 2003. 60p.

(compiladora). Biblioteca Escolar: conhecimentos que sustentem a prática. Belo Horizonte: Autêntica Editora, 2012. Cap. 2, 4 e 6.

et al. Biblioteca escolar como espaço de produção do conhecimento: parâmetros para bibliotecas escolares. Belo Horizonte: Universidade Federal de Minas Gerais, 2010. <Http://alb.com.br/arquivomorto/edicoes_anteriores/anais15/Sem02/severinofarias.htm>. Acesso em: 21 ago. 2014.

CÔRTE, Adelaide Ramos e; BANDEIRA, Suelena Pinto: Biblioteca Escolar. Brasília, DF: Briquet de Lemos, 2011. Cap.1 e 8. 
HILLESHEIM, Araci Isaltina de Andrade; FACHIN, Gleisy Regina Bories. Biblioteca escolar e a leitura. In: Rev. ACB: Biblioteconomia em Santa Catarina. Florianópolis:ACB, v.8/9, p.35-45, 2003/2004.

MORO, Eliane L. da Silva; ESTABEL, Lizandra Brasil. Mediadores de leitura na família, na escola, na biblioteca, na bibliodiversidade. In: Neves, Iara C. B.; Moro, Eliane L. da Silva; Estabel, Lizandra Brasil (orgs.). Mediadores de leitura na bibliodiversidade. Porto Alegre: Evangraf/SEAD/UFRGS, 2012.

PINHEIRO, Mariza Inês da Silva. Classificação em cores: uma metodologia inovadora na organização das bibliotecas escolares do município de Rondonópolis-MT. RDBCI, Campinas, SP, v. 7, n. 1, ago. 2009.ISSN 1678-765X. Disponível em:<http://www.sbu.unicamp.br/seer/ojs/index.php/rbci/article/view/449/307>. Acesso em:06 jul. 2015.

; RODRIGUES, Luciléia R. Queiroz. Bibliotecário nas escolas: Um bem que faz bem ao futuro das crianças: Rev. ACB: Biblioteconomia em Santa Catarina. Florianópolis, v. 19, n. 2, p. 260271, jul. /dez.2014. Disponível em: <http://revista.acbsc.org.br/racb/article/view/968/pdf_104>. Acesso em: 05/02/2014.

\section{SCHOOL LIBRARY IN CHILDREN'S VISION OF ELEMENTARY}

Abstract: The purpose of this study was to know the reality lived by students of Elementary School in the Library of the State School Professor Renilda Silva Moraes, located in the city of Rondonópolis, Mato Grosso. To that end, we set out to check the level of student satisfaction with regard to the general organization of the library, color classification system, reading and interaction activities between student / librarian / teacher. The search for the information was through a questionnaire with open and closed questions. The school library should be considered a space with an educational function of a school and, therefore, should be inserted in the pedagogical projects as an ally in the teaching-learning process. With regard to the activities developed to encourage reading, it was found that the library offers several motivational activities, such as: story time, reading corner; text production; Interpretation of texts; Reading stand; theater; Reader of the year, dances, confection of books, drawings contest, selection of subjects in magazines, reader of the year award. Thus, the results revealed that students approve all proposed activities if they are very satisfied with the work done at the Library.

Keywords: School library. User satisfaction. Encouraging reading.

RECEBIDO EM: 14-07-2016

ACEITO EM: 04-11-2016 